\title{
EMPODERAMENTO E FEMINISMO NEGRO: DECOLONIZANDO EPISTEMOLOGIAS E MENTALIDADES
}

\author{
Joice Berth* \\ Entrevista por Naira Pinheiro dos Santos** \\ Nilza Menezes*** \\ Priscila Kikuchi Campanaro****
}

Joice Berth é feminista interseccional negra, arquiteta e urbanista, pós-graduada em Direito Urbanístico e assessora parlamentar. O conceito de empoderamento lhe é caro e se insere naquela que constitui, na perspectiva de Joice Berth, uma "revolução epistêmica", capaz não apenas de desconstruir, mas de construir, acrescentar, expandir "os limites do pensamento impregnado de racismo, que limita o pleno desenvolvimento humano da branquitude". O conceito de empoderamento, sua genealogia e aplicação, está no cerne do livro de sua autoria, "O que é Empoderamento", o terceiro da coleção "Feminismos Plurais", voltada à publicação de livros que abordam aspectos e perspectivas feministas, principalmente de mulheres negras e indígenas, coleção essa organizada pela feminista e ativista negra Djamila Ribeiro.

Já no início da genealogia do conceito que desenvolve no livro, Joice Berth denuncia o paternalismo como uma estratégia de manutenção do status quo opressor. Ele possibilita ao opressor perpetuar o seu poder e ainda se comprazer em fornecer alívio por meio de sua falsa

* Pós-graduada em Direito Urbanístico pela PUC- MG., feminista interseccional negra, assessora parlamentar.

** Doutora em Ciências da Religião e membro do grupo de pesquisa em gênero e religião Mandrágora/Netmal.

*** Doutora em Ciências da Religião e membro do grupo de pesquisa em gênero e religião Mandrágora/Netmal.

**** Doutora em Ciências da Religião e membro do grupo de pesquisa em gênero e religião Mandrágora/Netmal, coordenadora do Teoria Feminista: por uma teoria feminista descolonizada BERTH, Joice. O que é empoderamento? São Paulo: Pólen Livros, 2019.

Mandrágora, v.26, n. 1, 2020, p. 225-232 
(e fugaz) generosidade, como bem lembra Freire em sua pedagogia dos oprimidos. É esse tipo de prática paternalista que levaria tantas mulheres negras a aderir a religiões evangélicas?

Como aponta Joice Berth, o liberalismo aborda o empoderamento numa perspectiva individual e individualista, sendo que, para que seja efetivamente libertador, o empoderamento não pode visar senão o coletivo, embora contemple, necessariamente, também transformações individuais. O coletivo implica reconhecer a existência de diversas opressões, de raça/etnia, gênero, orientação sexual, classe social, nacionalidade, religião, idade, condição física, dentre outras, não hierarquizáveis, quer se cruzem ou não, para além daquelas individuais ou mesmo de um determinado grupo social. Daí o valor da empatia como instrumento político, mas a empatia em face da opressão, não é capaz de produzir, por si só, o empoderamento. Sendo uma construção coletiva, jamais unicamente individual, a crítica radical, o dar a voz a pessoas/grupos sociais afetados pela opressão e a sororidade são, na perspectiva de Joice Berth, alguns dos elementos imprescindíveis à desconstrução das estruturas de dominação em todos os seus aspectos, dentre os quais o social, o cognitivo, o psicológico, o político e o econômico. Ela pontua que não se trata de fornecer instrumentos aos indivíduos e/ou grupos oprimidos, mas dest@s os obterem por si mesm@s, desvendando capacidades adormecidas pelos sistemas de opressão.

Ao dar voz às mulheres negras que conheceram o empoderamento antes mesmo do termo ter sido cunhado, ao dar voz a feministas negras na construção do conceito de empoderamento, Joice Berth ilumina o nosso percurso na luta feminista contra as múltiplas opressões, dentre os quais o racismo religioso. Embora muit@s ainda acreditem que os discursos religiosos são atemporais, as religiões não estão fora do contexto social em que são praticadas, de modo que reproduzem as desigualdades aí presentes, ao menos no que diz respeito às suas vertentes hegemônicas. Nessas condições, podem as religiões concorrer para o empoderamento de mulheres ou mesmo lhes possibilitar acessar ferramentas para tal? "Decolonizar epistemes e mentalidades" representa, sem dúvida, um grande desafio. Com a palavra, Joice Berth. 
Priscila Kikuchi Campanaro: Joice, quais são as principais contribuições da coleção feminismos plurais para as discussões sobre a cultura de branquitude dentro do movimento e da produção teórica feminista? Joice Berth: Creio que a principal contribuição da Coleção Feminismos Plurais seja trazer para a visibilidade do grande público os discursos esclarecedores, porém, rejeitados e/ ou subestimados pela produção editorial hegemônica, que é majoritariamente branca. Quando pensamos em Empoderamento, por exemplo, que é um conceito muito sério e com alto potencial emancipatório e de reparação de perdas sociais históricas, como tem sido tratado? Como mero discurso de autoajuda, que aprofunda a crença na meritocracia e não discute as hierarquias de poder e as relações que ela desenvolve. Não fosse a Coleção Feminismos Plurais, esse esvaziamento continuaria transitando livremente, minando as possibilidades de trabalho do conceito, que é absolutamente aplicável. Ou seja, a Coleção, ao dar voz a intelectuais negros/as sérios/ as, das mais diversas áreas de estudo e pesquisa, a leva até as pessoas que buscam conhecimento de qualidade e, cada livro traz um resgate de outros/as intelectuais brancos/as e não brancos/as, através de sua bibliografia vasta e qualificada. Por isso tenho a convicção de que é pelo menos o início de uma revolução epistêmica há muito esperada e que não contribui apenas para a visibilidade do pensamento intelectual da negritude, contribui também para a expansão dos limites do pensamento impregnado de racismo, que limita o pleno desenvolvimento humano da branquitude.

Naira Pinheiro dos Santos: Enquanto arquiteta e feminista negra, qual ou quais conexões você estabelece entre racismo e arquitetura? Como o racismo intervém na disposição da cidade? E as religiões, elas concorrem de alguma maneira para o processo de configuração do espaço urbano?

Joice Berth: Os espaços das cidades, bem como suas construções são altamente discursivos e trabalham com símbolos, significados e significantes (traçando um paralelo entre conceitos da psicanálise aqui). Nesse sentido, se tivemos uma construção de cidades iniciada no pós-abolição e que coincidiu com epistemologia eugenista e suas 
bifurcações, é muito "inocente" pensar que essas influências não estiveram atuantes nas suas mais variadas formas. Quando pensamos, por exemplo, nas políticas de branqueamento, onde ela se encaixou na formação das cidades? Se encaixou nos planos higienistas de urbanização, que juntavam ao mesmo tempo a exaltação da Europa como padrão de qualidade e a varredura dos escravizados e dos europeus considerados de segunda categoria para as partes insalubres e distantes do centro, tomado pela burguesia pós-colonial. Eu parto de Anibal Quijano na pesquisa que trago no meu próximo livro, que fala em Colonialidade do Saber, do Poder e do Ser, para afirmar que também tivemos a colonialidade do espaço urbano, a colonialidade do território, definindo a localização das identidades subalternizadas e seus limites de usufruto da cidade como um todo. Essa e muitas outras conexões podemos fazer entre racismo e arquitetura/urbanismo.

Priscila Kikuchi Campanaro: Considerando que o feminismo negro tem descolonizado alguns saberes e apresentado um caminho epistemológico plural, como esse movimento pode influenciar positivamente os estudos sobre gênero e religião no nosso país?

Joice Berth: Eu sou uma feminista negra e decolonial. Então penso que é preciso entender que descolonizar não é o mesmo que decolonizar, embora alguns achem que é só um detalhe gramatical. Descolonizados estamos desde que, cronologicamente falando, o período colonial terminou. Acontece que houve uma absorção muito mais profunda e uma espécie de enraizamento de toda a "alma" colonial e ela ainda atua livremente, mesmo em lugares onde se fala em descolonizar. Nesse sentido, descolonizar seria se descolar da colonização e suas infomações ou se afastar disso. Decolonizar é romper com a colonialidade, entendendo que até na formação da nossa personalidade ela pode estar atuante. Por exemplo, no Brasil temos o Candomblé, que discretamente rejeita a Umbanda (e vice-versa) alegando um embranquecimento de suas práticas. O Candomblé fala da e valoriza muito a ancestralidade, mas ignora que na Umbanda esse discurso também é vivenciado, apesar da continuidade do sincretismo que embranquece os Orixás de maneira 
acrítica. Ora, ambas as religiões são marcadas pela perseguição no âmbito do Racismo Religioso, então o discurso separatista vem da coIonialidade do saber e do ser, que faz com que as pessoas se coloquem como verdade única. Pai Tata Tancredo, grande defensor da Umbanda Omoloko é esquecido pelo branqueamento da Umbanda e desprezado pela negligência do Candomblé. Então eu penso que ainda não estamos totalmente libertos do cativeiro epistemológico imposto pela lógica do pensamento eurocêntrico, embora o feminismo negro esteja propondo outros olhares para problemas históricos. O próprio feminismo negro não está livre da colonialidade, embora esteja mais inteirado de seus caminhos. É preciso simultaneamente decolonizar as epistemes e as mentalidades que, mesmo quando se debruçam sobre produções negras, mantém uma bruma da atitude do colonizador nas ações e/ou omissões.

Naira Pinheiro dos Santos: Joice, você trabalha com o conceito de empoderamento. Como essa perspectiva teórica contribui ou pode contribuir na luta de campo contra o racismo e as desigualdades de gênero?

Joice Berth: Essa perspectiva teórica é um poderoso aporte para diversos trabalhos sociopolíticos necessários para o resgate do poder social das minorias oprimidas, bem como para sua emancipação holística. Ao trabalhar as dimensões estruturais da vida dos grupos minoritários, em conjunto e isoladamente, permite que todos os resquícios da atuação da colonialidade sejam compreendidos e dizimados. Só através da compreensão profunda sobre nosso lugar social e a atuação do poder, tal qual o conhecemos, enquanto formador da hierarquia social, bem como determinante das relações que construímos, onde todas estão completamente sujeitas a essa lógica essencialmente desigual, podemos pensar em estratégias econômicas, políticas, cognitivas e psíquicas de rompimento e reestruturação social, sempre visando a emancipação social de grupos minoritários, que são os que estão sob ação direta desses fatores.

Naira Pinheiro dos Santos: Tive a feliz oportunidade de estar presente na conferência ${ }^{2}$ que você fez em Montpellier, França, em 18/novembro/

Conferência organizada por Aurélie Knüfer, grupo CRISES Centre de Recherches Interdisciplinaires en Sciences Humaines et Sociales, Université Paul-Valéry Montpellier 3. 
2019, junto com a Djamila Ribeiro. Na ocasião você falou sobre a atuação de neopentecostais junto a populações vulneráveis no Brasil. Você poderia explicar aqui a sua visão acerca dessa questão? Como você avalia o impacto de tal atuação sobre as mulheres negras? Tendo em vista a sua concepção de empoderamento enquanto instrumento de subversão de relações sociais de dominação, você vislumbra estratégias de empoderamento, em curso ou em potência, por mulheres negras pentecostais?

Joice Berth: As religiões neopentecostais são hoje para a sociedade o que o catolicismo foi na idade média, um canal de esvaziamento e neutralização do poder sociopolítico de grupos já marcados pelas opressões estruturais. Obviamente não estou falando da religião em si, mas da atuação política que se disfarça de religião e aliena, subjuga e deteriora a capacidade de percepção das práticas que ela evoca. Muitos me contestam sob o argumento de que essas igrejas cumprem o papel do estado na vida das pessoas oprimidas. Isso tem um nome: assistencialismo. E assistencialismo não tem como foco emancipar nem recuperar ninguém. Ao mesmo tempo em que preenchem as falhas do estado, trabalham ativamente para manter essas falhas, que não são falhas, são projetos opressores de sociedade. E é óbvio que mulheres negras, a base da pirâmide social, estejam em maior aderência no contingente dessas igrejas. A grande perversidade é justamente essa: o alto poder que elas exercem sobre a subjetividade fragilizada de mulheres que sofrem todo tipo de abandono da sociedade, têm suas famílias dizimadas e suas possibilidades econômicas e políticas reduzidas a pó. Eu chamo de linchamento sociopsíquico, pois alicia a mente se valendo do açoite social sobre o corpo negro. As estratégias de empoderamento visam a emancipação completa através da conscientização desses processos de atuação do poder opressor. E o grande perigo, nesse contexto em que vivemos, é justamente o esvaziamento do conceito de empoderamento no seu cerne, sendo preenchido com meias verdades, discurso meritocrático e de autoajuda camuflados. Já li uma matéria há algum tempo atrás, onde mulheres evangélicas se diziam empoderadas porque tinham poder de compra e eram submissas aos maridos por escolha própria, mesmo "bancando" as despesas da casa. Ou seja, onde está a emancipação aí? É um grande desafio. 
Nilza Menezes: E quanto às religiões de matriz afro, você percebe assimetrias de gênero nas práticas religiosas? Em caso positivo, como elas se estruturam e/ou reproduzem?

Joice Berth: As práticas das religiões de matriz africana, pela própria cultura ancestral da matrilinearidade, pode ter outro caminho. Oyeronke Oyewumi, feminista nigeriana, discute as diferenças de gênero entre mulheres ocidentais e mulheres pertencentes à cultura Yorubá, refletindo, em um de seus artigos, sobre a expressão "mãe solteira". Segundo ela, para a cultura Yorubá, a maternidade é uma espécie de alta patente social e não está necessariamente relacionada a estado civil, por exemplo. Isso nos mostra que a cultura falopatriarcal não é padrão de consideração de maternidade saudável, muito pelo contrário, por aqui se esvazia todo o poder feminino (ou o resto dele) tão logo a mulher se torna mãe. A grande "pedra no sapato" das práticas religiosas de matriz africana, que permeiam historicamente nosso contexto, seria justamente a colonialidade atuante na psiquê de muitos/as adeptos/as, que reproduzem as práticas opressoras assimiladas ao longo da história e que estão solidificadas no inconsciente coletivo. Nem todas as nossas ações são conscientes e depois de quase quatro séculos de escravização, os efeitos ainda são vivos e atuantes, inclusive sem o nosso controle. Por isso, nas minhas palestras tenho insistido no trabalho muito lúcido de empoderamento, em sua dimensão psicológica, pois ainda que estejamos lutando contra o que nos oprime, é perfeitamente possível que estejamos reforçando padrões que sequer sabemos que estão dentro de nós. E as religiões de matriz africana não estão isentas da reprodução dessas lógicas, ainda que Orixá seja um norteador de emancipação e totalmente oposto às formações hierárquicas ocidentais.

Naira Pinheiro dos Santos: Você considera que há incompatibilidade inerente entre religião e igualdade de gênero? A seu ver, as religiões de matriz africana podem cumprir um papel no empoderamento das mulheres negras no Brasil? 
Joice Berth: Eu considero que tudo pode ser reinventado e que as religiões estão marcadas pela ação consciente do ser humano, que manipula dogmas de acordo com seus interesses, além de lançar mão de estratégias de entorpecimento das massas sociais. Acredito que religião em si, é um canal de equilíbrio individual. É onde podemos encontrar caminhos para a paz e o equilíbrio. No entanto, ao longo da história, essas possibilidades foram cooptadas pelas necessidades de dominação do poder patriarcal. Tornaram-se instrumentos de escoamento do discurso de desvalorização e desumanização de mulheres, de pessoas negras, indígenas, etc. Allan Kardec tem textos onde afirma existir uma inferioridade espiritual de pessoas negras. O catolicismo, através das Santas, corrobora com a desvalorização da figura da mãe e coloca a mulher em uma lógica binária onde ou parimos ou somos errantes, além de esvaziar completamente a sexualidade da mulher como fonte exclusivamente de prazer. No filme "A maçã" da cineasta Samira Makhmalbaf, temos o caso real de duas irmãs cujo pai as confinou por 11 anos, a partir da crença em um trecho bíblico. Enfim, há diversos exemplos de que, mesmo com todas as resistências que se formam dentro dessas religiões, e que eu respeito muito, ainda aliciam e definem o pensamento e comportamento das massas que praticam seus dogmas de maneira acrítica. E as massas são mais fortes do que gostaríamos, no mau sentido. Eu gostaria de achar um modo de isolar as religiões dos efeitos e manobras dos discursos políticos, mas creio que isso só será possível quando a maioria das pessoas se conscientizarem dos perigos da manipulação de dogmas religiosos e nos seus efeitos catastróficos para o indivíduo e para a sociedade como um todo. 